\title{
ASPECTOS NUTRICIONAIS E FUNCIONAIS DO MORANGO
}

\section{NUTRITIONAL AND FUNCTIONAL ASPECTS OF THE STRAWBERRY}

\author{
QUINATO, Éricka Esteves ${ }^{1 *}$; DEGÁSPARI, Cláudia Helena ${ }^{2}$; VILELA, Regina Maria ${ }^{3}$
}

\begin{abstract}
${ }^{1}$ Aluna de Graduação do Curso de Nutrição da Universidade Tuiuti do Paraná, Rua Amazonas, 677, ap. 13 - 80610-030 Curitiba - PR e-mail: erickaquinato@yahoo.com.br

2 Professora Adjunta da Universidade Tuiuti do Paraná. e-mail: sensus@cwb.matrix.com.br

${ }^{3}$ Professora Adjunta da Universidade Tuiuti do Paraná. e-mail: regina.vilela@utp.br
\end{abstract}

\begin{abstract}
RESUMO
As frutas desempenham um papel muito importante em nossa alimentação. São fontes naturais de nutrientes, vitaminas e sais minerais, além de fornecerem fibras e apresentarem flavonóides que contribuem para a prevenção de doenças, como por exemplo, o combate ao câncer, doenças do trato gastro intestinal e também o envelhecimento precoce causado pelos radicais livres. Este artigo trata-se de uma revisão bibliográfica onde serão abordados os teores de vitaminas, fibras totais, fibras solúveis e insolúveis e compostos fenólicos presentes no morango em comparação com outras frutas e os agentes antinutricionais presentes no morango como ácido salicílico e ácido oxálico que merecem destaque especialmente pelas pessoas que são alérgicas a estes compostos.
\end{abstract}

Palavras-chave: morango; alimentos funcionais; propriedades nutricionais.

\begin{abstract}
The fruits have an important role in human feed. They are natural sources of nutrients, vitamins and minerals, besides supplying staple fibers and presenting flavonoids that contribute for the prevention of illnesses, as for example, the combat to the cancer, illnesses of the intestinal treatment gastric and also the precocious aging caused by the free radicals. This article is about a bibliographical revision where the texts of vitamins, total staple fibers will be boarded, soluble and insoluble staple fibers and phenolic composites present in the strawberry in comparison with other fruits and antinutricionals agents present in the strawberry as acid salicylic and acid oxalic that especially deserve prominence for the people who are allergics to these composites.
\end{abstract}

Key words: strawberry; functional food; nutritional proprieties.

\section{INTRODUÇÃO}

As frutas desempenham um papel muito importante em nossa alimentação. São fontes naturais de nutrientes, vitaminas e sais minerais, além de fornecerem fibras e outros nutrientes que contribuem para a prevenção de doenças, como por exemplo, o combate ao câncer de cólon. Recomenda-se a ingestão de 3 a 4 porções de frutas ao dia (TRIPLOV, 2006).

No que se refere ao câncer de estômago, é a segunda neoplasia de incidência mais comum e causa de morte por câncer no mundo. No entanto, é um dos poucos tumores cuja incidência e mortalidade vem registrando marcado declínio em vários países. Analisando globalmente, as taxas de incidência do câncer de estômago reduziram-se cerca de 30\% no período de 1960 a 1985. Índia, China e América do Norte foram regiões que apresentaram as maiores reduções, provavelmente relacionadas ao maior consumo de vegetais e frutas, entre outros fatores. Outras neoplasias merecem análises comparativas em relação ao seu padrão de distribuição no Brasil, são os tumores malignos de cólon e reto. Encontram-se entre as cinco primeiras causas de morte por câncer na população brasileira. A distribuição percentual de tumores malignos de cólon e reto aproximam-se dos registros 
encontrados nos países altamente industrializados. Há várias evidências de que a alimentação tem um papel importante nos estágios de iniciação, promoção e propagação do câncer, destacando-se entre outros fatores de risco. Entre as mortes por câncer atribuídas a fatores ambientais, a dieta contribui com cerca de 35\%. Acreditase que uma dieta adequada poderia prevenir de três a quatro milhões de casos novos de cânceres a cada ano. (GARÓFOLO et al., 2004).

Estas recomendações estão apresentadas na pirâmide de alimentos, que é dividida nos seguintes grupos: grãos, vegetais, frutas, azeites, produtos lácteos e carnes e feijões, dando-se destaque a quantidade de calorias adequadas e à atividade física (USDA, 2006).

Dentre os compostos bioativos estão os alimentos funcionais que são caracterizados como todo aquele que apresenta uma ou mais substâncias com funções fisiológicas e bioquímicas benéficas à saúde do homem (NEUMANN et al., 2000).

Planta herbácea, rasteira e perene da família Rosaceae, propagada por via vegetativa, através de estoIhos. Em geral, a cultura para produção de frutos é renovada anualmente. As abelhas são imprescindíveis para polinização. Botanicamente, a parte comestível é um pseudofruto, originário do receptáculo floral que se torna carnoso e suculento. Os frutos verdadeiros são pequenos aquênios, vulgarmente denominados "sementes". A parte comestível, adiante referida simplesmente por fruto, é rica em vitamina $\mathrm{C}$. O ácido elágico nela presente pode ter efeito medicinal (HERBÁRIO, 2005).

O morango apresenta matérias aromáticas que atuam nos nervos do olfato e do gosto aumentando o apetite. É uma fruta que apresenta tanto benefícios para a saúde como malefícios em alguns casos. Tem efeito estimulante do apetite, facilita a digestão e é excelente alimento para o fígado pelo seu elevado teor de açúcares naturais (HORTIFRUTI, 2006).

Além de estimular os processos de absorção do organismo infantil, o morango aumenta a resistência às infecções e tem ação anticancerígena (HORTIFRUTI, 2006).

As frutas e as hortaliças têm assumido posição de destaque nos estudos que envolvem a prevenção do câncer. Fazendo uma projeção na estimativa de prevenção, pode-se supor que o aumento no consumo de frutas e hortaliças promove uma redução na incidência global de câncer, que varia de 7\% (estimativa conservadora) a $31 \%$ (estimativa otimista) (GARÓFOLO et al., 2004).

Os morangos podem ser estocados inteiros na geladeira por poucos dias (quando fatiados perdem gradativamente a vitamina C). Recomenda-se lavar a fruta pouco antes de servir para evitar o mofo e prevenir surtos de diarréia infecciosa (HERBÁRIO, 2005).

O mofo cinzento representa uma importante e freqüente doença do morangueiro, sob condições de alta umidade e temperaturas amenas. Causado pelo fungo Botrytis cinerea, caracteriza-se por ser uma doença típica de frutos (TÖFOLI \& DOMINGUES, 2005). Esse mofo é formado por vírus e bactérias que podem ser as causadoras da diarréia infecciosa que é uma das causas mais importantes de morbidade e mortalidade na infância em todo o mundo, levando-se em conta aspectos locais na sua prevalência e patogenicidade (SABRÁ, 2002).

\section{TEOR VITAMÍNICO}

O morango é uma fonte importante de algumas vitaminas como a vitamina $\mathrm{C}$, vitamina $\mathrm{A}$ e folatos.

O morango, entre outras frutas representa uma vasta fonte de vitaminas, o que pode ser observado nas TABELA 1 e 2, fazendo um paralelo de comparação.

TABELA 01 - CONTEÚDO POR 100 G DAS VITAMINAS LIPOSSOLÚVEIS CONTIDAS EM ALGUNS FRUTOS.

\begin{tabular}{cccccc}
\hline Fruto & Vitamina A & Vitamina D & Vitamina E & $\begin{array}{c}\text { Equivalente } \\
\beta \text {-caroteno }\end{array}$ & Retinol \\
\hline $\begin{array}{c}\text { Morango } \\
\text { natural }\end{array}$ & $3,00 \mu \mathrm{g}$ & $0 \mu \mathrm{g}$ & $0,2 \mathrm{mg}$ & $40 \mu \mathrm{g}$ & $0 \mu \mathrm{g}$ \\
\hline $\begin{array}{c}\text { Maçã natural } \\
\text { com casca }\end{array}$ & $3,00 \mu \mathrm{g}$ & $0 \mu \mathrm{g}$ & $0,5 \mathrm{mg}$ & $70 \mu \mathrm{g}$ & $0 \mu \mathrm{g}$ \\
\hline Laranja natural & $20,17 \mu \mathrm{g}$ & $0 \mu \mathrm{g}$ & $0,24 \mathrm{mg}$ & $120 \mu \mathrm{g}$ & $0 \mu \mathrm{g}$ \\
\hline Mamão papaya & $37,00 \mu \mathrm{g}$ & $0 \mu \mathrm{g}$ & n. d. & $948 \mu \mathrm{g}$ & $0 \mu \mathrm{g}$ \\
\hline
\end{tabular}

FONTE: FAVIER ET AL. , 1999; PINHEIRO ET AL., 2004. 
TABELA 02 - CONTEÚDO POR 100 G DAS VITAMINAS HIDROSSOLÚVEIS CONTIDAS EM ALGUNS FRUTOS.

\begin{tabular}{ccccccccc}
\hline Fruto & $\begin{array}{c}\text { Vitamina } \\
\text { C }\end{array}$ & Tiamina & Riboflavina & Niacina & $\begin{array}{c}\text { Ácido } \\
\text { pantotênico }\end{array}$ & $\begin{array}{c}\text { Vitamina } \\
\mathbf{B}_{6}\end{array}$ & $\begin{array}{c}\text { Vitamina } \\
\mathbf{B}_{12}\end{array}$ & Folatos \\
\hline $\begin{array}{c}\text { Morango } \\
\text { natural }\end{array}$ & $70,00 \mathrm{mg}$ & $0,02 \mathrm{mg}$ & $0,03 \mathrm{mg}$ & $0,5 \mathrm{mg}$ & $0,34 \mathrm{mg}$ & $0,06 \mathrm{mg}$ & $0 \mu \mathrm{g}$ & $62 \mu \mathrm{g}$ \\
\hline $\begin{array}{c}\text { Maçã } \\
\text { natural } \\
\text { com casca }\end{array}$ & $5 \mathrm{mg}$ & $0,03 \mathrm{mg}$ & $0,02 \mathrm{mg}$ & $0,1 \mathrm{mg}$ & $0,06 \mathrm{mg}$ & $0,05 \mathrm{mg}$ & $0 \mu \mathrm{g}$ & $13 \mu \mathrm{g}$ \\
\hline $\begin{array}{c}\text { Laranja } \\
\text { natural }\end{array}$ & $53 \mathrm{mg}$ & $0,09 \mathrm{mg}$ & $0,04 \mathrm{mg}$ & $0,28 \mathrm{mg}$ & $0,3 \mathrm{mg}$ & $0,06 \mathrm{mg}$ & $0 \mu \mathrm{g}$ & $30 \mu \mathrm{g}$ \\
\hline $\begin{array}{c}\text { Mamão } \\
\text { papaya }\end{array}$ & $64 \mathrm{mg}$ & $0,03 \mathrm{mg}$ & $0,03 \mathrm{mg}$ & $0,4 \mathrm{mg}$ & $0,22 \mathrm{mg}$ & $0,02 \mathrm{mg}$ & $0 \mu \mathrm{g}$ & $45 \mu \mathrm{gg}$ \\
\hline
\end{tabular}

FONTE: FAVIER ET AL., 1999; PINHEIRO ET AL., 2004.

Um consumo diário de 300 a 400mg de vitamina C (5 a 7 vezes a RDA de $60 \mathrm{mg}$ ) pode ajudar a prolongar a vida. Em um estudo, 11.348 adultos, com idades entre 25 e 74 anos, foram examinados durante o período de 1971 a 1974 e acompanhados até 1984. O grupo de indivíduos que consumiu cerca de 300 a 400 mg de vitamina C diariamente, quando comparado ao que consumiu menos de $50 \mathrm{mg}$, apresentou uma incidência de $42 \%$ menor ocorrência de óbitos de variada natureza e $45 \%$ menor ocorrência de óbitos por doenças cardíacas. Isto significou uma expectativa maior de vida de até seis anos para homens e de um ano para mulheres. A vitamina $\mathrm{C}$ age como um varredor de radicais livres e de antioxidantes. Os radicais livres atacam lipídios, carboidratos, proteínas, enzimas e DNA, causando oxidação e alterações que podem gerar lesão celular. O ácido ascórbico é um dos antioxidantes protetores e agentes redutores mais importantes do organismo. Eles reduzem a ação dos radicais livres, minorando-lhes possíveis prejuízos (KATCH \& MCARDLE, 1996).

Os folatos representam um grupo variado de substâncias de ocorrência natural, apresentando-se principalmente na forma de pteroil heptaglutamato. Os alimentos com maior concentração de folatos são fígados, nozes, verduras frescas, legumes, frutas cítricas e morangos. O cozimento prolongado dos alimentos pode destruir até $90 \%$ do folato dos alimentos (GARCIA, 1998).

\section{TEOR DE FIBRAS}

O morango é rico em pectina e outras fibras solúveis que ajudam a baixar o colesterol. Contém bioflavonóides, como a antocianina (de coloração avermelhada) e o ácido elágico, substâncias que podem ajudar a evitar alguns tipos de câncer. Como o ácido elágico não é destruído pelo cozimento, até uma torta e uma geléia de morango são nutritivas (HERBÁRIO, 2005).

A evolução do conhecimento científico permitiu concluir que a normalidade digestiva, bem como, a prevenção e o tratamento de doenças como a constipação, a diverticulite, a hipercolesterolemia, a hiperglicemia, a obesidade, o câncer do intestino grosso e da mama, estão relacionados, em parte, à ingestão de fibra alimentar. Contudo, os diversos constituintes da fibra alimentar não têm o mesmo efeito ou ação fisiológica. A fibra solúvel contribui para o aumento do volume intraluminal, no entanto, tem pouco efeito, em contraste com a fibra insolúvel, no peso e no volume fecal (RAUPP et al., 2000).

A ingestão de fibra deve consistir de uma mistura de fibra solúvel e insolúvel, uma proporção de 3:1 de insolúvel para solúvel, como se encontra na natureza. Esta ingestão pode ser obtida com cinco porções ou mais de frutas e vegetais e seis porções diárias de pães de grão integral, cereais e leguminosas (MAHAN, 1998). 
A TABELA 03 exibe a composição centesimal ( $\mathrm{g} / 100 \mathrm{~g}$ de material integral) de fibras totais do morango, maçã, mamão e laranja pêra (MENDES et al, 1995).

TABELA 3 - COMPOSIÇÃO CENTESIMAL DE FIBRAS TOTAIS CONTIDAS EM ALGUNS FRUTOS.

\begin{tabular}{cc}
\hline COMPONENTES & QUANTIDADES \\
\hline Morango & $1,82 \mathrm{~g}$ \\
\hline Maçã Com casca & $2,14 \mathrm{~g}$ \\
Sem casca & $1,69 \mathrm{~g}$ \\
\hline Mamão & $1,53 \mathrm{~g}$ \\
\hline Laranja Pêra Com bagaço & $1,54 \mathrm{~g}$ \\
Sem bagaço & $0,92 \mathrm{~g}$ \\
\hline
\end{tabular}

FONTE: MENDES, 1995.

\subsection{FIBRAS SOLÚVEIS}

Incluem pectinas, mucilagens e algumas hemiceluloses. As pectinas são encontradas principalmente em frutas e vegetais, especialmente maçãs, laranjas e cenouras. Outras formas de fibras solúveis ocorrem no farelo de aveia, cevada e leguminosas. A influência das fibras solúveis em eventos do trato alimentar está relacionada à sua habilidade de reter água e formar géis e também ao seu papel como substrato para a fermentação de bactérias colônicas (MAHAN, 1998).

A TABELA 4 exibe o teor de fibras solúveis do morango, maçã, mamão e laranja pêra ( $\mathrm{g} / 100 \mathrm{~g}$ de material integral) (MENDES et al., 1995).

TABELA 4 - TEOR DE FIBRAS SOLÚVEIS CONTIDAS EM ALGUNS FRUTOS.

\begin{tabular}{ccccc}
\hline Fruta & Pectina solúvel & Protopectina & Pectina total & Fibra Solúvel Total \\
\hline Morango & $0,23 \mathrm{~g}$ & $0,27 \mathrm{~g}$ & $0,50 \mathrm{~g}$ & $1,00 \mathrm{~g}$ \\
\hline Maçã & & & & \\
Com casca & $0,04 \mathrm{~g}$ & $0,96 \mathrm{~g}$ & $1,00 \mathrm{~g}$ & $2,00 \mathrm{~g}$ \\
Sem casca & $0,11 \mathrm{~g}$ & $0,82 \mathrm{~g}$ & $0,93 \mathrm{~g}$ & $1,86 \mathrm{~g}$ \\
\hline Mamão & $0,21 \mathrm{~g}$ & $0,56 \mathrm{~g}$ & $0,77 \mathrm{~g}$ & $1,54 \mathrm{~g}$ \\
\hline Laranja Pêra & & & & \\
Com bagaço & - & $0,94 \mathrm{~g}$ & $0,94 \mathrm{~g}$ & $1,88 \mathrm{~g}$ \\
Sem bagaço & - & $0,65 \mathrm{~g}$ & $0,65 \mathrm{~g}$ & $1,3 \mathrm{~g}$ \\
\hline
\end{tabular}

FONTE: MENDES ET AL, 1995.

\subsection{FIBRAS INSOLÚVEIS}

Consistem principalmente de celulose e algumas hemiceluloses. Dão estrutura às células vegetais e são encontradas em todos os tipos de material vegetal; entretanto, sua maior fonte está nas camadas externas de grãos de cereais. A lignina, um material não carboidrato que algumas vezes está incluído na determinação de fibras, é o componente principal das árvores e fornece estrutura às porções lenhosas das plantas. Constitui uma porção muito pequena da dieta (1 $\mathrm{g} / \mathrm{dia}$ ) e é encontrada principalmente em frutas com cascas e sementes comestíveis (MAHAN, 1998).

As sementes de morango contêm fibras insolúveis, que ajudam a evitar a constipação. Entretanto, elas podem ser prejudiciais para pessoas com distúrbios intestinais como a diverticulose, uma doença em que pequenas bolsas se inflamam ao longo da parede intestinal (HERBÁRIO, 2005). 
A TABELA 5 exibe o teor de fibras insolúveis do morango, maçã, mamão e laranja pêra (g/100g de material integral) (MENDES et al., 1995).

TABELA 05 - TEOR DE FIBRAS INSOLÚVEIS CONTIDAS EM ALGUNS FRUTOS.

\begin{tabular}{ccccc}
\hline Frutos & Celulose & Hemicelulose & Lignina & Fibra Insolúvel Total \\
\hline Morango & $0,48 \mathrm{~g}$ & $0,41 \mathrm{~g}$ & $0,43 \mathrm{~g}$ & $1,32 \mathrm{~g}$ \\
\hline Maçã & & & & \\
Com casca & $0,66 \mathrm{~g}$ & $0,31 \mathrm{~g}$ & $0,17 \mathrm{~g}$ & $1,14 \mathrm{~g}$ \\
Sem casca & $0,53 \mathrm{~g}$ & $0,19 \mathrm{~g}$ & $0,04 \mathrm{~g}$ & $0,76 \mathrm{~g}$ \\
\hline Mamão & $0,62 \mathrm{~g}$ & $0,01 \mathrm{~g}$ & $0,13 \mathrm{~g}$ & $0,76 \mathrm{~g}$ \\
\hline Laranja Pêra Com & & & & $0,6 \mathrm{~g}$ \\
bagaço & $0,54 \mathrm{~g}$ & $0,01 \mathrm{~g}$ & $0,05 \mathrm{~g}$ & $0,27 \mathrm{~g}$ \\
Sem bagaço & $0,25 \mathrm{~g}$ & - & $0,02 \mathrm{~g}$ & \\
\hline
\end{tabular}

FONTE: MENDES ET AL, 1995.

\section{TEOR DE COMPOSTOS FENÓLICOS}

Os compostos fenólicos são facilmente oxidáveis, tanto através de enzimas vegetais específicas quanto por influência de metais (como ferro e manganês), da luz e do calor, ou em meio alcalino, ocasionando o escurecimento de suas soluções ou dos compostos isolados (SIMÕES et al., 2000).

Os compostos fenólicos são os maiores responsáveis pela atividade antioxidante em frutos. Embora a vitamina C seja considerada por alguns autores como o maior contribuinte na atividade antioxidante, alguns colaboradores demonstraram que a contribuição da vitamina $C$ na determinação da atividade antioxidante de onze frutos é baixa $e$ afirmaram que a maior contribuição para a atividade antioxidante total de frutos se deve à composição de compostos fitoquímicos. Observa-se a influência dos compostos fitoquímicos, principalmente os pigmentos antociânicos, na atividade antioxidante. As polpas de frutas que não os contêm, como o abacaxi, a graviola, o cupuaçu e o maracujá, apresentam valores menores de atividade antioxidante. Portanto os frutos analisados demonstram correlação direta entre o conteúdo total de compostos fenólicos e a atividade antioxidante (KUSKOSKI et al., 2006).

Pouco ainda é conhecido sobre a absorção, biodisponibilidade e metabolismo dos flavonóides na concentração normalmente ingerida na dieta humana, mas acredita-se que eles não apresentam toxicidade e, se ainda permanecerem biologicamente ativos in vivo, os flavonóides podem previnir a citoxicidade e a lipoperoxidação (YUNES \& CALIXTO, 2001).

As propriedades antioxidantes dos flavonóides têm, assim, atraídas a atenção para a nutrição preventiva, pois eles protegem os constituintes alimentares contra o dano oxidativo, podendo também contribuir para a prevenção de importantes patologias, como doenças cardiovasculares, envelhecimento, cânceres e outras (YUNES \& CALIXTO, 2001).

Estes compostos fenólicos são um dos maiores grupos de componentes dietéticos não essenciais e têm suas pesquisas justificadas por estarem associados à inibição de doenças crônico-degenerativas, como aterosclerose e câncer. A bioatividade dos fenólicos pode estar relacionada com o potencial antioxidante destes compostos, aos quais são atribuídas as seguintes características: quelar metais e seqüestrar radicais livres. Contudo, os compostos fenólicos podem também promover reação oxidativa in vitro, agindo como pró-oxidantes, ao atuarem sobre metais, reduzindo-os e aumentando a formação de radicais livres e peróxidos (MOREIRA \& MANCINI-FILHO, 2004).

Sob o ponto de vista nutricional, os flavonóides são reconhecidamente agentes antioxidantes capazes de inibir a oxidação de lipoproteínas de baixa densidade - LDL, além destes reduzirem significativamente as tendências a doenças trombóticas (DEGÁSPARI \& WASZCZYNSKYJ, 2004). 
TABELA 6 exibe a quantidade de flavonóides presentes no morango (USDA, 2003).

TABELA 6 - QUANTIDADE DOS DIVERSOS TIPOS DE FLAVONÓIDES ENCONTRADOS NO MORANGO CONGELADO E CRU.

\begin{tabular}{|c|c|c|c|}
\hline DESCRIÇÃO & SUBCLASSE & FLAVONÖIDE & QUANTIDADE MÉDIA \\
\hline \multirow{8}{*}{$\begin{array}{l}\text { Morangos, } \\
\text { congelados não } \\
\text { adoçados }\end{array}$} & \multirow{2}{*}{ Flavonolóis } & Kampferol & 0,53 \\
\hline & & Quercetina & 0,44 \\
\hline & \multirow{6}{*}{ Flavan-3-óis } & (-)-Epicatequina & 0,00 \\
\hline & & (-)-Epicatequina 3-galato & 0,00 \\
\hline & & (-)-Epigalatocatequina & 0,00 \\
\hline & & (-)-Epigalatocatequina 3-galato & 0,00 \\
\hline & & (+)-Catequina & 4,47 \\
\hline & & (+)-Galatocatequina & 0,00 \\
\hline \multirow[t]{5}{*}{ Morangos crus } & \multirow{2}{*}{ Flavonas } & Apigenina & 0,00 \\
\hline & & Luteolina & 0,00 \\
\hline & \multirow{3}{*}{ Flavonolóis } & Kampferol & 0,79 \\
\hline & & Mircetina & 0,00 \\
\hline & & Quercetina & 0,65 \\
\hline
\end{tabular}

FONTE: USDA, 2003.

Neste quadro pode-se perceber a diferença dos valores entre o morango congelado e o morango natural. O morango congelado apresenta menores valores de flavonóis porque estes nutrientes se perdem através do processamento, da temperatura, dentre outros, ou seja, só aproximadamente $67 \%$ deste flavonóide estão presentes no morango congelado o que indica que há perda de aproximadamente $33 \%$ após o processo.

\section{AGENTES ANTINUTRICIONAIS}

O morango contém um alérgeno comum e um salicilato natural (um composto semelhante à aspirina), em decorrência muitas pessoas são alérgicas a esta fruta. Ele também contém ácido oxálico, que pode ocasionar cálculos nos rins e bexiga em pessoas suscetíveis, além de reduzir a absorção de ferro e cálcio no organismo (HERBÁRIO, 2005).

\section{1. ÁCIDO OXÁLICO}

É encontrado nas plantas do gênero Oxalis e é considerado um produto anti-tártaro, usado na eliminação de ferrugem em metais, mármores e outras pedras; para fixação de corantes em tecidos (mordente); obtenção de corantes; fabricação de tintas de escrever; branqueamento e curtição industrial de couros; branqueamento de têxteis, papeis, cortiça e palha e produção de oxalatos (WIKIPÉDIA, 2006).

O ácido oxálico é um ácido orgânico encontrado em certos vegetais de folhas que se liga ao cálcio e inibe a sua absorção a partir destes alimentos (MAHAN, 1998).

Cerca de $80 \%$ dos cálculos são compostos de oxalato de cálcio (sozinho ou com um núcleo de fosfato de cálcio - hidroxiapatita) e são mais comuns em homens de meia idade (MAHAN, 1998).

Por isso, pessoas com tendência a formação de cálculos oxálicos não devem consumir exageradamente morango, dando-se destaque às pessoas com artrite, reumatismo e cálculos (MAHAN, 1998). 


\section{2. ÁCIDO SALICÍLICO OU SALICILATOS}

O ácido salicílico é uma substância comumente encontrada na aspirina e esta pode causar hipoglicemia em jejum (WILLIAMS, 1997).

Sabe-se que este ácido pode ter uma ação corrosiva nas paredes do estômago. Para contornar este efeito foi adicionado uma hidroxila diretamente ao anel aromático, dando origem a um éster acetato, chamado de ácido acetil-salicílico (AAS), menos corrosivo, mas também menos potente (WIKIPÉDIA, 2006).

\section{REFERÊNCIAS}

DEGÁSPARI, C. H. \& WASZCZYNSKYJ, N. Propriedades Antioxidantes de Compostos Fenólicos. Visão Acadêmica, Curitiba, v. 5, n.1, jan./jun. 2004.

FAVIER, et al. Repertório geral dos alimentos: tabelas de composição. São Paulo: Roca, 1999.

GARCIA, L. Y. C. Anemias Carencias na Infância. Disponível em: <http://www.pediatriasaopaulo.usp.br/upload/pdf/364.pdf>. Acesso em 02 de abril de 2007.

HERBÁRIO. Cultivo do Morango. Disponível em:

<http://www.herbario.com.br/dataherb12/morango.htm>. Acesso em 01 de setembro de 2006.

HORTIFRUTI. Morango. Disponível em:

<http://www.hortifruti.com.br/cgi-bin/t_vidaleve.asp?area=produtosdaestacao\&id=5>. Acesso em 30 de agosto de 2006.

KATCH, F. I. \& McARDLE, W. D. Nutrição, Exercício e Saúde. 4. ed. Rio de Janeiro: Medsi, 1996.

KUSKOSKI, et al. Frutos tropicais silvestres e polpas de frutas congeladas: atividade antioxidante, polifenóis e antocianinas. Ciência Rural, Santa Maria, v. 36, n. 4, jul./ago. 2006.

MAHAN, L. K. Krause: alimentos, nutrição \& dietoterapia. 9.ed. São Paulo: Roca, 1998.

MENDES, et al. Tabela de Composição de Alimentos. Niterói: EDUFF, 1995.

MOREIRA, A. V. B. \& MANCINI-FILHO, J. Influência dos compostos fenólicos de especiarias sobre a lipoperoxidação e o perfil lipídico de tecidos de ratos. Revista de Nutrição, Campinas, v. 17, n. 4, out./dez. 2004.

NEUMANN, et al. Alimentos saudáveis, Alimentos funcionais, Fármaco-alimentos, Nutracêuticos... Você ouviu falar neles? Hig. Aliment., São Paulo, v.14, n. 71, p. 19-23, 2000.

PINHEIRO, et al. Tabela para avaliação de consumo alimentar em medidas caseiras. 5.ed. São Paulo: Atheneu, 2004.

RAUPP et al. Propriedades funcionais-digestivas e nutricionais de polpa-refinada de maçã. Scientia Agricola, Piracicaba, v. 57, n. 3, jul./set. 2000.

SABRÁ, A. ECEP, ECET, ECEA, ECEH, ECEI, ECAD: a E. coli revisitada no contexto da diarréia aguda. Jornal de Pediatria, Porto Alegre, v. 78, n. 1, jan./fev. 2002.

SIMÕES, et al. Farmacognosia: da planta ao medicamento. 2. ed. Florianópolis: Editora da UFSC, 2000.

TÖFOLI, J. G. \& DOMINGUES, R. J. Morango: Controle adequado. Disponível em:

<http://www.biologico.sp.gov.br/artigos_tecnicos/morango.htm>. Acesso em 04 de junho de 2007.

TRIPLOV. Os livros de Walkyria. Disponível em: <http://www.triplov.com/walkyria/plantas/fruta.htm>. Acesso em 31 de agosto de 2006.

UNITED STATES DEPARTMENT OF AGRICULTURE. My pyramid. Disponível em:

<http://www.mypyramid.gov/index.html>. Acesso em 03 de novembro de 2006.

U.S. DEPARTMENT OF AGRICULTURE. USDA Database for the Flavonoid Content of Selected Foods. Março, 2003.

WIKIPÉDIA. Ácido Oxálico. Disponível em:

<http://pt.wikipedia.org/wiki/\%C3\%81cido_ox\%C3\%A1lico>. Acesso em 01 de setembro de 2006.

WIKIPÉDIA. Ácido Salicílico. Disponível em:

<http://pt.wikipedia.org/wiki/\%C3\%81cido_salic\%C3\%Adlico>. Acesso em 03 de novembro de 2006.

WILLIAMS, S. R. Fundamentos de Nutrição e Dietoterapia. Porto Alegre: Artmed, 1997.

YUNES, R. A. \& CALIXTO, J. B. Plantas Medicinais: sob a ótica da Química Medicinal Moderna. Chapecó: Argos, 2001. 